Journal of Applied Biology \& Biotechnology Vol. 2 (04), pp. 021-029, July-August, 2014

Available online at http://www.jabonline.in

DOI: $10.7324 / \mathrm{JABB} .2014 .2404$

ISSN: 2347-212X (cc) BY-NC-SA

\title{
Forensic Conception: DNA typing of FTA Spotted Samples
}

\author{
Patel Jignal ${ }^{1}$, Shaikh $\mathrm{MG}^{2}$ and Marjadi Darshan ${ }^{1}$ \\ ${ }^{1}$ Shree Ramkrishna Institute of Computer Education \& Applied Sciences, Surat, India. \\ ${ }^{2}$ DNA Division, Regional Forensic Science Laboratory Falsawadi, Surat-395002, Gujarat, India.
}

\begin{tabular}{l}
\hline ARTICLE INFO \\
\hline Article history: \\
Received on: $23 / 06 / 2014$ \\
Revised on: $26 / 07 / 2014$ \\
Accepted on: $10 / 08 / 2014$ \\
Available online: $27 / 08 / 2014$ \\
\hline
\end{tabular}

Key words:

DNA, FTA Cards, STR

Profile, Blood, Semen,

Saliva.

\begin{abstract}
Forensic labs globally face the same problem growing need to process a greater number and wider variety of samples for DNA analysis.DNA purification step has been thought to be essential for typing of STR DNA. However, this process is time-consuming, and there is a risk of unexpected cross-contamination during purification. There is a need, for each sample type, to develop new methodology that is not only faster but also more reliable than past procedures. FTA technologies provides use most reliable method for DNA extraction.FTA is a chemical treatment of paper, unique to Whatman Bioscience, and is used for the stabilization and storage of biological samples. The FTA matrix is chemically treated with proprietary reagents that lyse cells upon contact. FTA cards protect nucleic acids from nucleases, oxidation, UV damage and microbial and fungal attack. In forensic laboratory there is a need of such a method by which DNA can be extracted by simple method in less time. Here, the method is modified for semen and saliva samples for extraction of DNA on FTA classic cards for forensic use. All the samples were collected only on FTA Classic cards. After DNA extraction, amplification of DNA was carried out then the amplified DNA was placed into DNA sequencer for STR profiling. STR peaks were obtained from the all biological samples such as Blood, Saliva and Semen in our study thus there is no need of other kits available for collection of samples. On the basis of results, it is considered that modified procedure using an FTA card can be applicable to routine work.
\end{abstract}

\section{INTRODUCTION}

FTA® technology is a novel method designed to simplify the collection, shipment, archiving and purification of nucleic acid from a wide variety of biological sources [1]. FTA cards are impregnated with a patented chemical formula that lyses cell membranes and denatures proteins on contact [2]. Nucleic acid are physically entrapped, immobilized and stabilized for storage at room temperature.FTA cards protect nucleic acids from nucleases, oxidation, UV damage and microbial and fungal attack. Infectious pathogens, including blood-borne pathogens in samples applied to FTA cards are rendered inactive on contact [3]. Cells in biological samples deposited on FTA cards lyse on contact with the matrix, and DNA is captured on the card.DNA is protected from environmental and enzymatic damage by the FTA chemicals. Whatman FTA technology consists of two distinct chemistries, both of which have the ability to lyse cells on contact, denature proteins, and protect DNA from degradation. FTA contains chemical denaturants and a free radical scavenger; FTA Elute contains a chaotropic

\section{* Corresponding Author}

Address: B/301, Shyam complex, near Ayodhya nagri, New adajan road, Surat-395009, India. Email: jimmupate130@gmail.com salt. With FTA, the DNA remains tightly bound while proteins and inhibitors are washed from the matrix. With FTA Elute, proteins remain tightly bound while DNA is eluted from the matrix. There are three options for DNA analysis with FTA cards: direct amplification, standard amplification with rinsing ("punchin" method), and extraction of DNA from the card. With FTA Elute, eluted DNA can be used for STR analysis (standard amplification), sequencing, and real-time PCR applications. Both FTA and FTA Elute cards are available as Indicating cards for use with clear samples, such as buccal cells or saliva.

The cards include a pink (FTA) or purple (FTA Elute) indicating dye that turns to white when a clear sample is applied [4].The next step after applying sample on FTA card is purification; FTA purification reagent is available for it. After this DNA amplification is carry out with PCR protocols. Amplified products are ready for the STR profiling. Pharmaceutical companies use FTA to collect and archive human DNA samples for clinical drug trials. Nature conserverationists use FTA to collect bird DNA from jet engines to determine the flight patterns of specific species [7]. Scientists hunting for new plant species use FTA in the field to collect and safely transport samples. Governmental agencies use FTA to sample food products while ranchers use FTA to track disease within multiple herd generations [8]. 


\section{SHORT TANDEM REPEATS (STRS)}

The human genome with 3 billion base pairs in size harbors genetically relevant information, which is essential for each individual but, appears to represent only $10 \%$ of the human genome [5]. The human genome is full of repeated DNA sequences. These repeated sequences come in various sizes and are classified according to the length of the core repeat units, the number of contiguous repeat units, and/or the overall length of the repeat region. DNA regions with short repeat units (usually 2-6 bp in length) are called Short Tandem Repeats (STR). STRs are found surrounding the chromosomal centromere (the structural center of the chromosomes). STRs have proven to have several benefits that make them especially suitable for human identification.

A short tandem repeat (STR) is a type of DNA polymorphism where short sequences of DNA are repeated. STRs are usually considered "junk DNA" because they are introns and do not code for protein. The number of times a DNA sequence is repeated for a given STR is variable between different individuals and thus, STRs are often useful for forensic or genealogical studies.

For human identification purposes, it is important to have DNA markers that exhibit the highest possible variation in order to discriminate between samples. It is often challenging to obtain PCR amplification products from forensic samples because either the DNA in those samples is degraded, or mixed, such as in a sexual assault case.

The smaller size of STR alleles makes STR markers better candidates for use in forensic applications, in which degraded DNA is common. PCR amplification of degraded DNA samples can be better accomplished with smaller target product sizes.

Because of their smaller size, STR alleles can also be separated from other chromosomal locations more easily to ensure closely linked loci are not chosen. Closely linked loci do not follow the predictable pattern of random distribution in the population, making statistical analysis difficult.

STR alleles also have lower mutation rates, which makes the data more stable and predictable [6]. The variety of alleles present in a population is such that a high degree of discrimination among individuals in the population may be obtained when multiple STR loci are examined [10].

Because of these characteristics, STRs with higher power of discrimination are chosen for human identification in forensic cases on a regular basis [6]. It is used to identify victim, perpetrator, missing persons, and others. The methodology was developed in parallel with the autosomal STR analysis for human identification purposes and evaluated in a very similar way for forensic analysis [9].

Beginning in 1996, the FBI Laboratory launched a nationwide forensic science effort to establish core STR loci for inclusion within the national database known as CODIS (Combined DNA Index System). The 13 CODIS loci are CSF1PO, FGA, TH01, TPOX, VWA, D3S1358, D5S818, D7S820,
D8S1179, D13S317, D16S539, D18S51 and D21S11. These loci are nationally and internationally recognized as the standard for human identification [6].

Helene C. Johnson et al (April 2009) described method for DNA elution from buccal cells stored on Whatman FTA Classic Cards using a modified methanol fixation method. This revised method was tested in comparison with the standard Whatman FTA protocol for both buccal cells on Whatman FTA Classic Card and blood spots [11,12]. This comparative study demonstrates that the methanol method was consistent for each biological sample and the FTA method showed a marked decrease in yield for the blood spots. The quality of genomic DNA eluted after methanol fixation was determined through PCR amplification and sequencing of human TYR gene exons [13,14]

Elizabeth Milne et al (Feb 2006) done Buccal DNA Collection and Comparison of Buccal Swabs with FTA Cards. They conclude, FTA cards are a robust DNA collection method that produces usable DNA for PCR more reliably than do buccal swabs. The collection of material for the FTA card is simple and pleasant compared with swabs $[15,16]$, mouthwash $[17,18,19]$ or cytobrushes.

Su Jeong Park et al(March 2008) gave method for Direct STR Ampification From Whole Blood and Blood- or SalivaSpotted FTA ${ }^{\circledR}$ without DNA Purification. They report a new method for short tandem repeat(STR) amplification using a newly developed direct PCR buffer, Any Direct, Which can amplify STR loci from whole blood and blood- or saliva- spotted FTA $®$ cards without DNA purification [20,21]. All amplification result from 50 blood spots fully matched those from corresponding purified DNA, showing no locus or allele drop-out in any of the STR loci of AmpFISTR Identifier $®[22,23,24]$. However, in 19 of 50 saliva spots, no or poor amplification occurred under the normal elution conditions.

\section{METHODOLOGY}

\subsection{Material required}

- Whatman FTA Classic Cards

- Whatman FTA purification reagent (cat no. WB120204)

- $\quad 1.2 \mathrm{~mm}$ diameter Harris micro punch

- $\quad \mathrm{TE}^{-1}$ buffer(10mM Tris-HCL, 0.1mM EDTA, pH 8.0)

- $\quad$ AmpFLSTR ${ }^{\circledR}$ Identifiler® PCR Amplification Kit

- $\quad$ The GeneAmp® PCR System 9700

- $\quad 3130$ Genetic Analyser

$>$ Blood, Semen and Saliva samples were collected conveniently from the cases of RFSL Surat.

\subsection{Sample application to FTA Cards}

First, label the FTA card with the appropriate sample identification. All the samples were taken on the FTA Classic Cards only, although there is a kit available for Buccal cells from Whatman. Then, drop the blood, semen and saliva samples onto the card in a concentric circular motion within the spotted circle. 
(Avoid "puddling" of the liquid sample, as it will overload the chemicals on the card. Also, do not rub or smear the blood onto the card.) Allow the samples to dry for about one hour at room temperature. (Do NOT heat, Dried blood spots will appear much darker than freshly spotted ones. If the sample is to be archived, place card in a Multi-Barrier pouch with desiccant or store in humidity controlled, cool, dry environment.)

\subsection{Removing a sample disc from an FTA® card}

Always ensure that the sample applied is dry before taking a punch. Place the FTA Classic Card on a cutting mat. (For cards with outer paper layers, ensure the mat is directly beneath the FTA Card with no paper layer in between.) Place the tip of a coring device, e.g., a Harris $1.2 \mathrm{~mm}$ Micro-punch, over the area to be sampled. (Do NOT depress the ejection plunger at this time.) Press down firmly on barrel of the coring device and twist to cut a disc out of the card. Once the disc was in the corer, transferred the disc to the desired PCR tube or tray by depressing the ejection plunger and ejected the disc. In order to ensure there is no crosscontamination between samples, the coring device can be cleaned using three methods.

\subsubsection{Cleaning the cover tip}

1. Rinse the tip with ethanol between samples and dry with a sterile wipe

2. Take one punch from blank filter paper or an unspotted area of the FTA card between samples

3. Clean the tip of the punch with a blow of compressed air between samples.

\subsection{Preparing an FTA Disc for PCR Analysis}

Take sample disc from the dried spot following the instruction given above. Place disc in PCR amplification tube. In extraction of Sperm DNA, 2 discs were taken from FTA card and for Saliva samples 3 discs were taken from the card. Add $200 \mu \mathrm{l}$ of FTA purification reagent to PCR tube. Incubate for 5 minutes at room temperature. (The tube may be given moderate manual mixing if desired.) Removed and discarded all spent FTA purification reagent using a pipette. Repeat steps 2-4 twice, for a total of three washes with FTA purification reagent. Add $200 \mu \mathrm{l}$ of $\mathrm{TE}^{-1}$ Buffer (10mM Tris-HCL, 0.1mM EDTA, $\mathrm{pH}$ 8.0) Incubate for 5 minutes at room temperature. Remove and discard all spent $\mathrm{TE}^{-1}$ Buffer with a pipette. Repeat steps 6-8 once, for a total of two washes with $\mathrm{TE}^{-1}$ Buffer. Allow disc to dry at room temperature for about one hour (or at $56^{\circ} \mathrm{C}$ for 10 minutes) before performing PCR.

\subsection{PCR Analysis}

The washed and dry disc was ready for PCR analysis using standard protocols. The disc was included in the PCR reaction. (There was no need to change reaction volume due to the presence of the disc.) PCR cycles were increased to 28 from 24. (Which is mentioned in standard protocol) For PCR analysis of genomic DNA on a $1.2 \mathrm{~mm}$ disc of FTA, $10 \mu \mathrm{l}$ of FTA a reaction volume used. (25-50 $\mu \mathrm{l}$ is recommended in standard protocol.)

\subsection{STR(Short Tandem Repeats) Analysis}

In 96 well microtitreplate, $10 \mu \mathrm{l}$ formamide and $0.3 \mu \mathrm{l}$ LIZ 500 were added for one sample. $2 \mu \mathrm{l}$ of amplified DNA was added in to respected well. The plate was subjected to PCR for denaturing step for $5 \mathrm{~min}$. After this step plate was placed into freezer for $2 \mathrm{~min}$. Then, the plate was placed in DNA sequencer for profiling.

\section{RESULTS AND DISCUSSION}

33 samples of different cases of regional forensic science laboratory were studied. The images are showing different results/ profiles. Some of the samples gave full profile while some samples gave partially positive result. There were also some samples which gave negative result.

Figure: 1-Ladder DNA. This image shows alleles of ladder DNA in upper portion and the peaks in lower portion shows that the comparison with alleles.

Figure: 2-Control DNA: This is the image of control DNA 99474, available in the kit and showing the whole DNA profile.

Figure: 3-Sample: 1. Sample-1 was a Blood sample of Person-1. From the blood sample peaks of 5 STR were obtained out of 16 .

Figure: 4-Sample: 4. Sample-4 was a Blood sample of Person-2. From this sample whole profile was obtained.

Figure: 5-Sample: 5. Sample-5 was a Semen sample of Person-2. From this sample whole profile was obtained.

Figure: 6-Sample: 6. Sample-6 was a Saliva sample of Person-2. From this sample whole profile was obtained.

Figure: 7-Sample: 7. Sample-7 was a Blood sample of Person3.This sample gave negative results. Peaks were not obtained for any STR.

Statistical analysis was done using SPSS Version 20.00

For this kind of categorical data chi-square test is used for analysis of data.

Fisher's Exact Test has shown the significance of 0.091 which is not significant at the confidence interval of $.95(\mathrm{p}<.05)$. This shows that there is no significant difference in the results between blood and semen \& blood and saliva, which suggest that the FTA DNA extraction method which is used to extract DNA from blood sample on FTA classic card can also be used to extract DNA from semen and saliva. Spearman's correlation has given the value of 1.0. So there is positive correlation between the results of blood sample and saliva as well as semen. The method of FTA DNA extraction has shown positive results in $90.91 \%$ of blood, $90.91 \%$ of saliva and $90.91 \%$ of semen samples. So the test has shown good reliability as it has shown positive results in $>90 \%$ of samples.

The method has got good sensitivity for extraction of DNA from all samples so it can be used. 


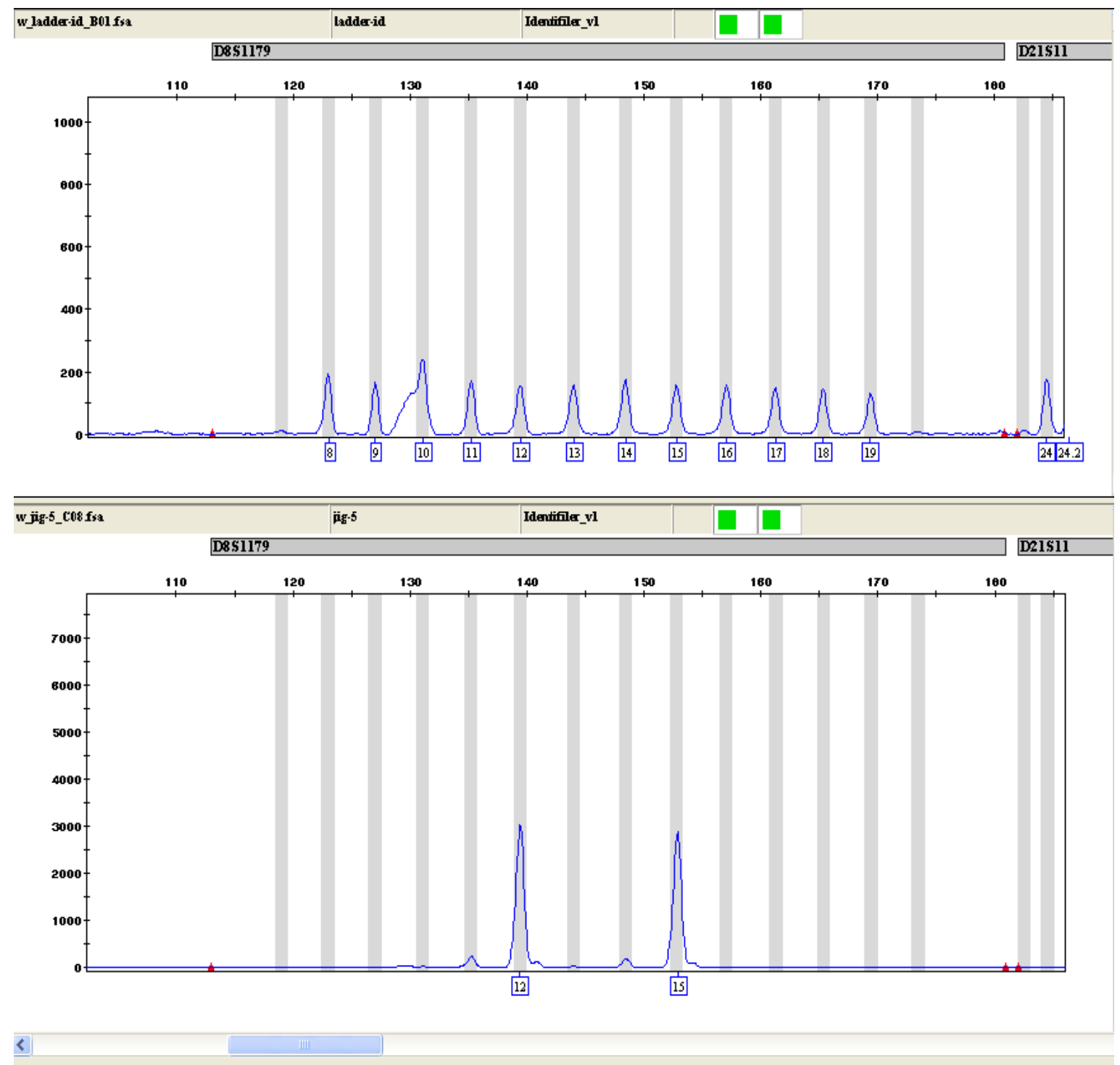

Fig. :1-Ladder DNA. This image shows alleles of ladder DNA in upper portion and the peaks in lower portion shows that the comparison with alleles.

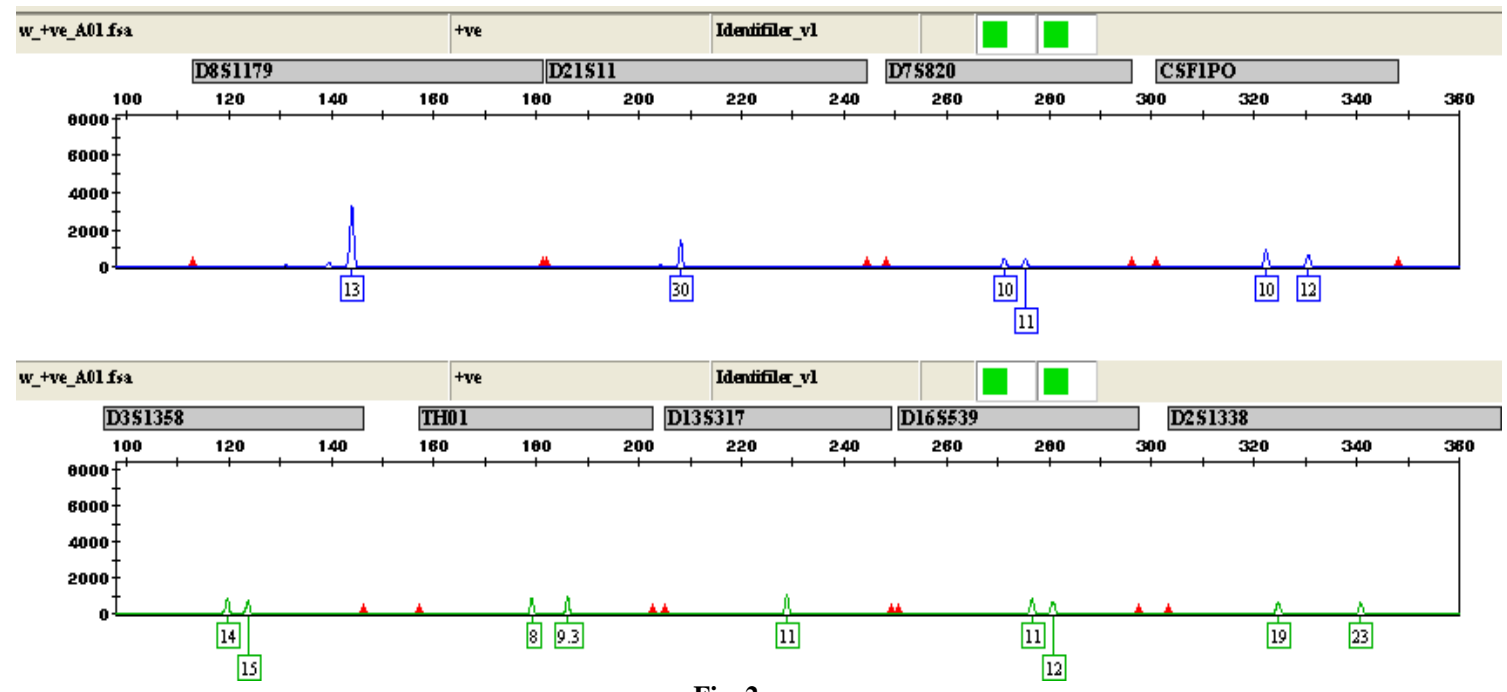

Fig. 2: ...... 


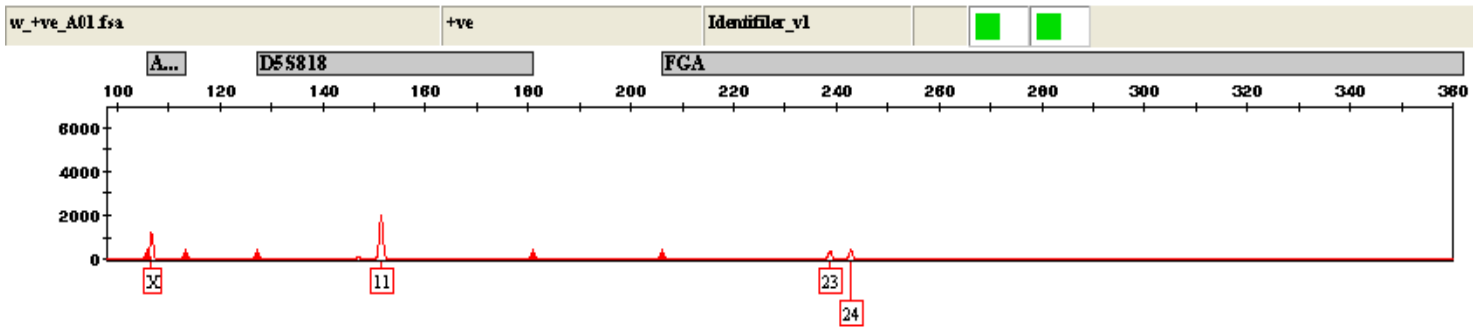

Fig. 2: Control DNA: This is the image of control DNA 99474, available in the kit and showing the whole DNA profile.
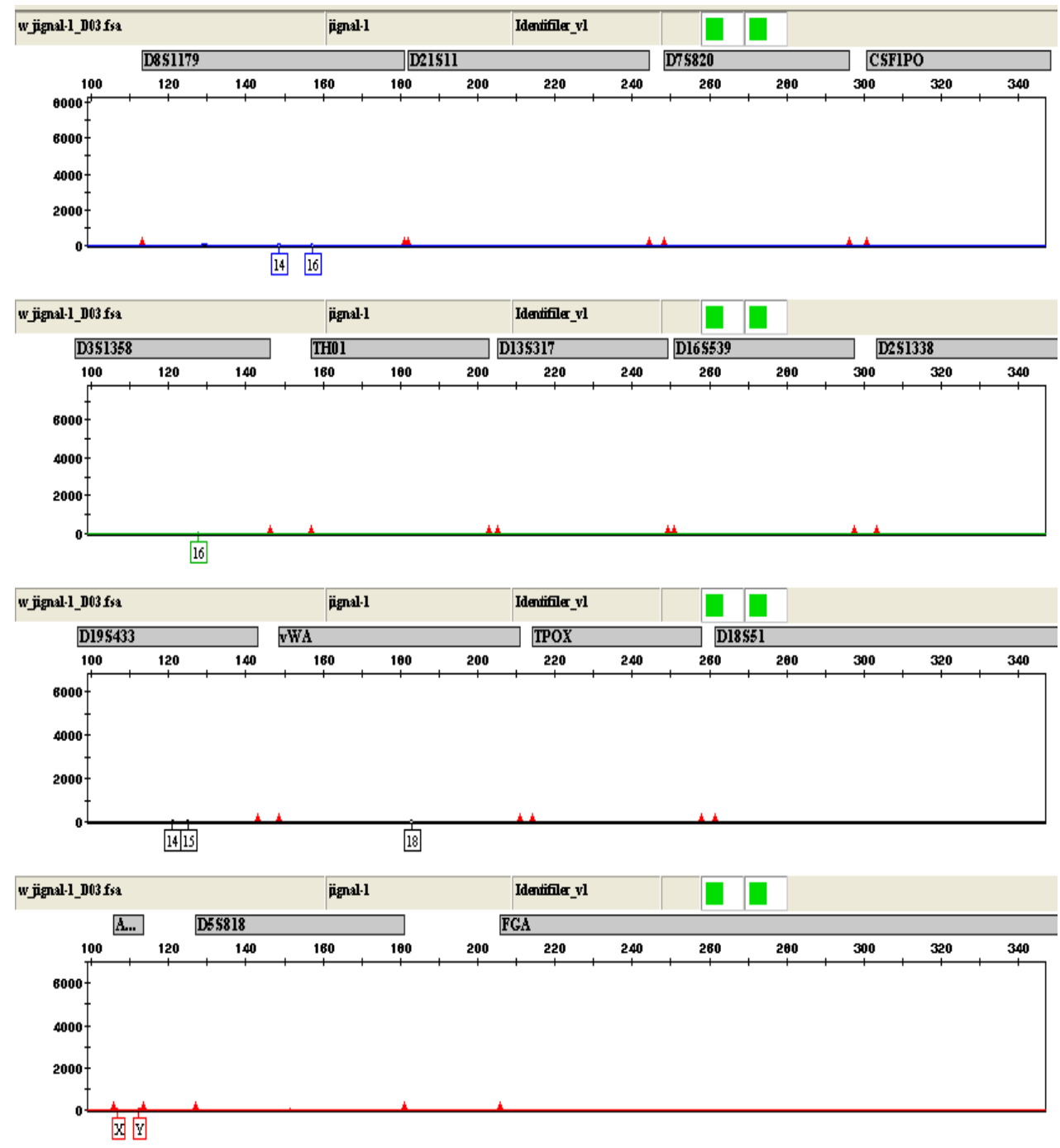

Fig. 3: Sample: 1. Sample-1 was a Blood sample of Person-1. From the blood sample peaks of 5 STR were obtained out of 16. 


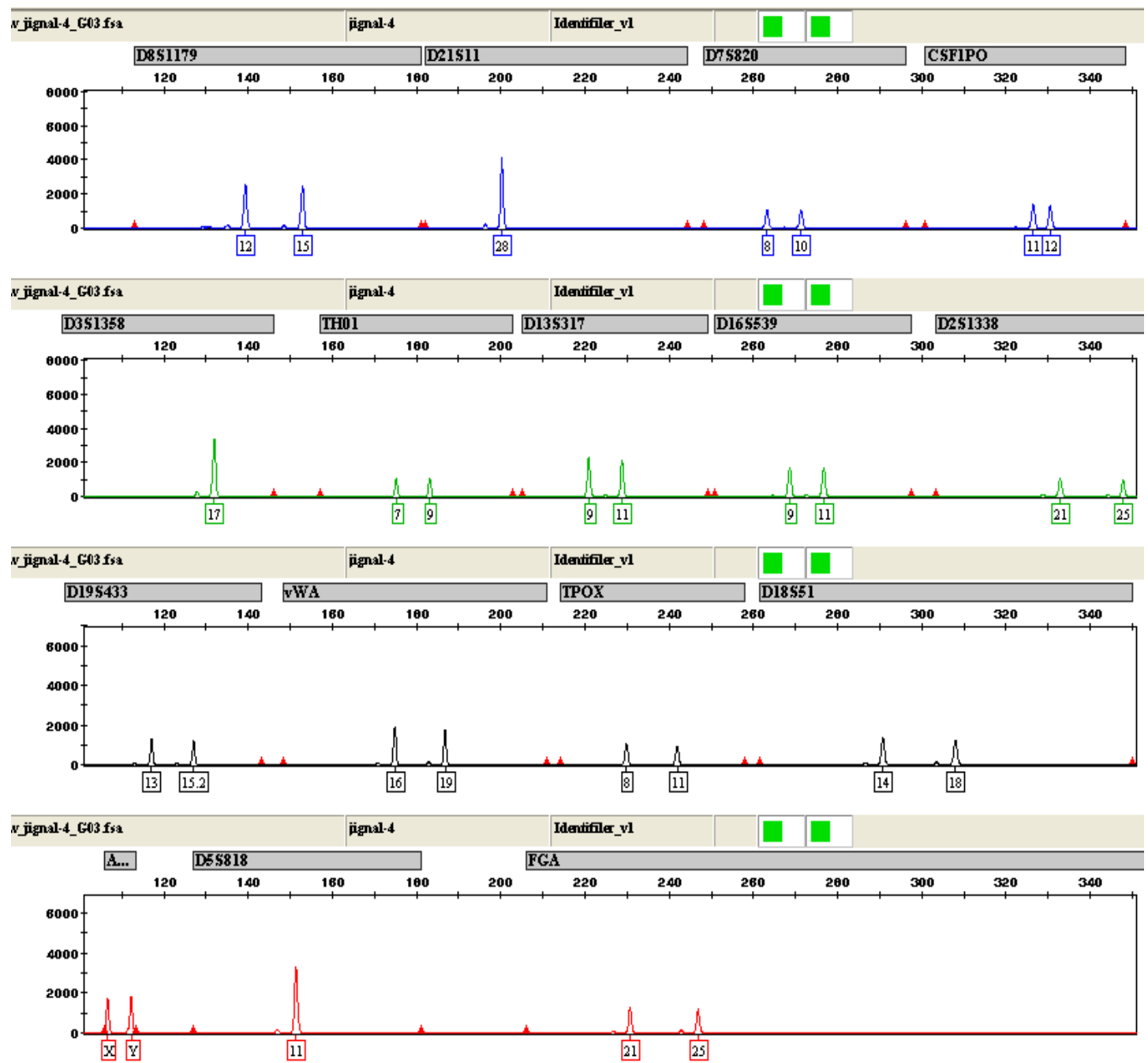

Fig. 4: Sample: 4. Sample-4 was a Blood sample of Person-2. From this sample whole profile was obtained.
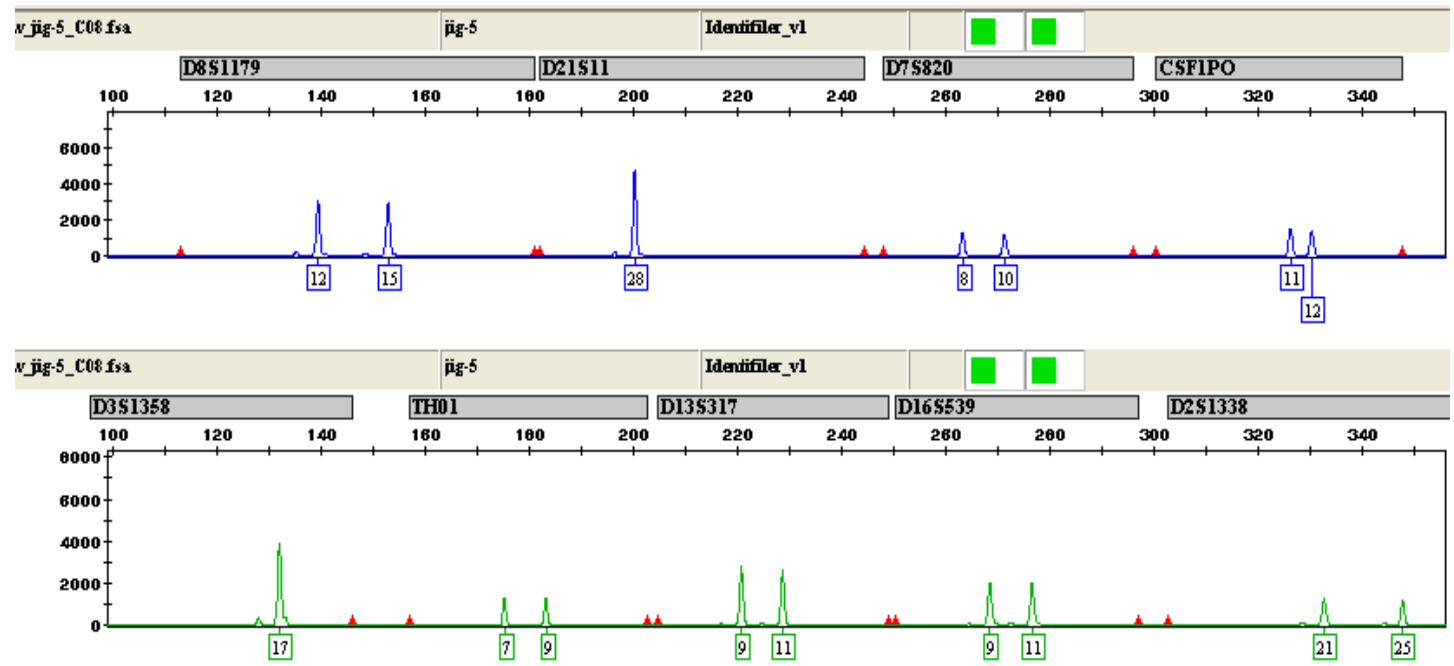

Fig. 5..... 


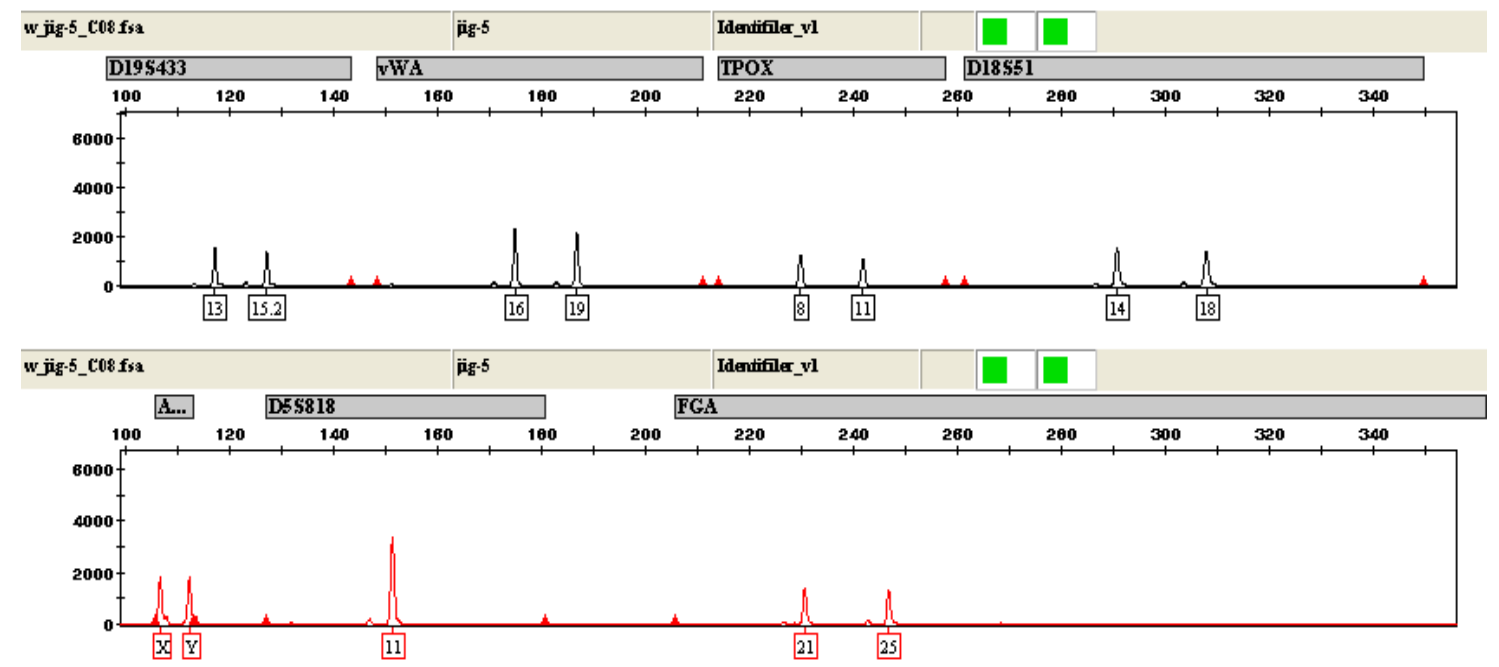

Fig. 5: Sample: 5. Sample-5 was a Semen sample of Person-2. From this sample whole profile was obtained.
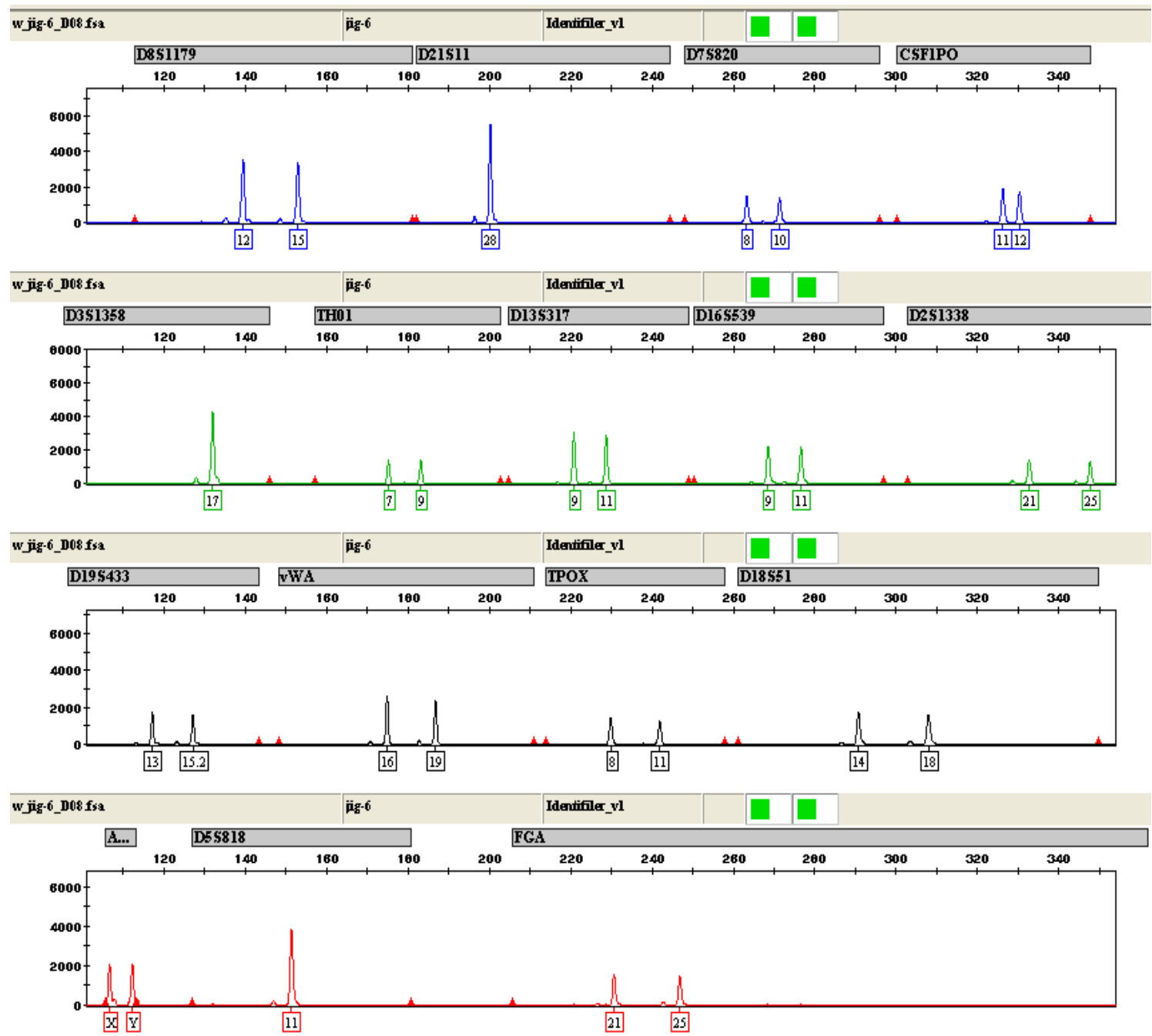

Fig. 6: Sample: 6. Sample-6 was a Saliva sample of Person-2. From this sample whole profile was obtained. 

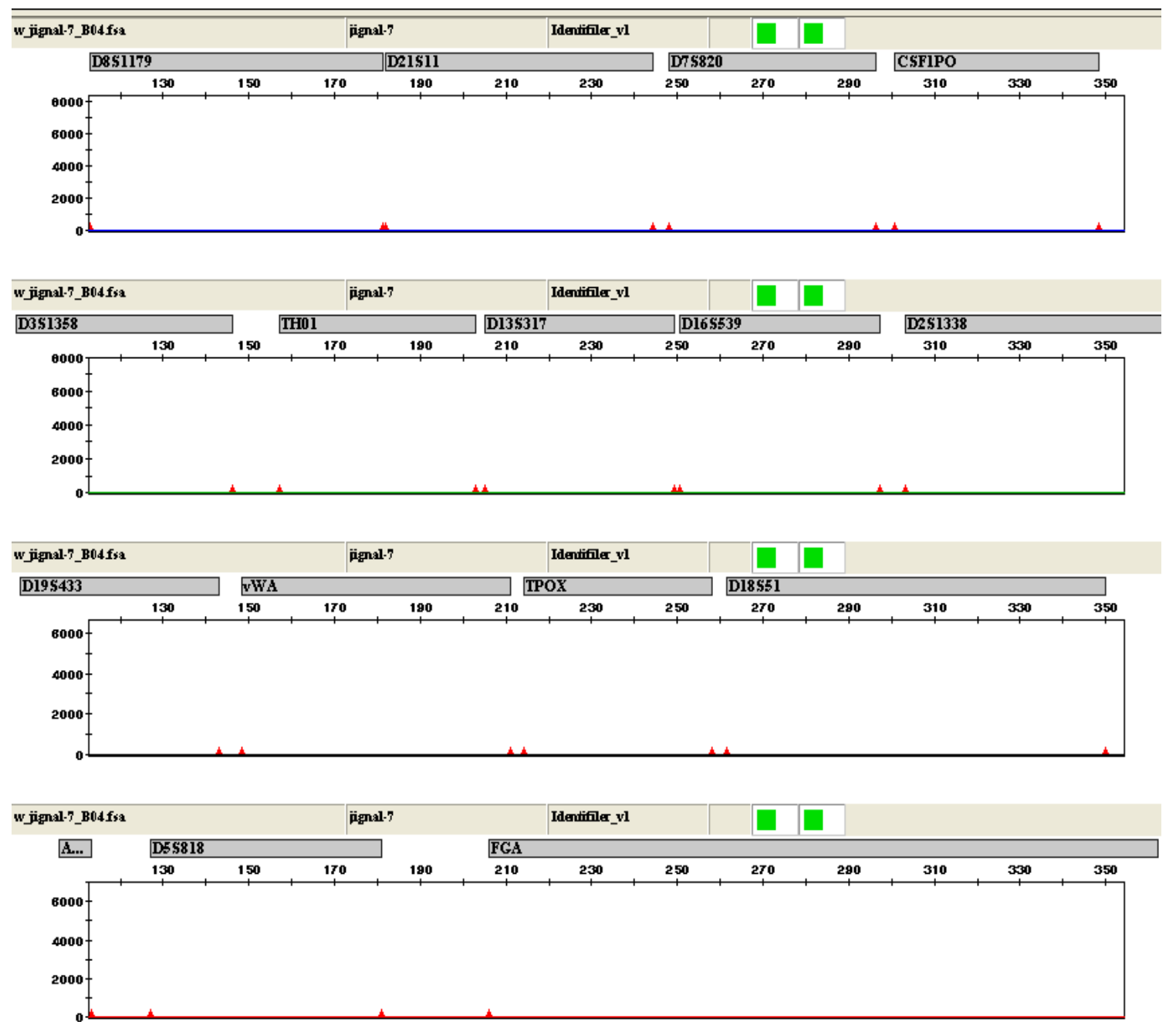

Fig. 7: Sample: 7. Sample-7 was a Blood sample of Person-3.This sample gave negative results. Peaks were not obtained for any STR.

\section{CONCLUSION}

DNA was extracted from the Blood, Saliva and Semen samples by FTA method and STR typing was done. As the results suggests sample-1 was Blood sample, obtained peak for 5 STR out of 16 STR. This could happen may be due to the sample was not parceled with proper anticoagulant. Another reason for these results is the samples were taken from the cases of forensic laboratory. So there is a chain of procedures. The samples were collected at hospital after the report filed against the suspect. Then the samples were transported to the laboratory. After that the samples were analyzed in to the laboratory. This procedure takes time and in between there are chances of the putrification of the samples. Thus proper extraction cannot be possible, and due to this reason amplification and typing also affects. And in profile peak of all STR cannot obtained. Sample-2 was semen sample, for this sample peak of 7 STR were obtained. For sample-3 peaks of 8 STR were obtained. It was sample of saliva. There were some samples which gave negative results, which were sample-7, sample-8 and sample-33 that are Blood, Semen and Saliva respectively. Sample-9 was saliva and it gave 14 STR out of 16.
Sample-19, 20, 21 gave 8, 10, 9 STR respectively. In the samples of saliva and semen it could be happened that the samples were contaminated prior to applied on FTA cards thus, there are chances of the degradation of the samples. Rest of all samples gave full profile of 16 STR.

Thus we can conclude that the FTA method for DNA extraction on classic card is reliable method. It can be use for saliva samples as well as semen samples. For saliva sample, there is a kit available also but using this method there is no need for the kit for buccal cell collection.

All samples were collected on classic card thus cost of the whole process becomes less. Another factor is time, in forensic laboratory there is a need of such a process which gives result of multiple samples in less time, FTA method is the method which give result in less time. Here we modify method for the saliva and semen sample. Results demonstrate that FTA is a practical, economical and sensitive method for sampling, storage and retrieval of samples and genomic sequences, when working under controlled conditions and in the field. 


\section{REFERENCES}

1. Yoshida K, Sekiguchi K, Mizuno N, Kasai K, Sakai I, Sato H, Seta S. The modified method of two-step differential extraction of sperm and vaginal epithelial cell DNA from vaginal fluid mixed with semen. Forensic Sci Int 1995; 72:25-33.

2. Whatman Inc. [2002]; FTA Protocols: Collect, Transport, Archive and Access Nucleic Acids - All at Room Temperature; WB120047; Available at www.whatman.com

3. Whatman Inc. [2002]; FTA Protocol BD08, Preparing an FTA® Disc for DNA Analysis, Available at www.whatman.com

4. Whatman Inc. [2011]; Whatman FTA technology overview (Brochure). GE Healthcare Life Sciences, UK limited.

5. Pankaj Shrivastava, Veena Ben Trivedi, Anil K Singh and N.Mishra Application of DNA fingerprinting technology in forensic investigation. International Journal of Scientific and Research Publications, Volume 2, Issue 10, October 2012.

6. forensicdnacenter.com[Internet].DNA Diagnostic Center, DNA testing system, Short tandem repeats[1995 - 2008], Available at www.forensicdnacenter.com

7. Whatman Inc. [2011]; FTA cards from GE Healthcare are chemically coated matrices that have been shown to preserve DNA more efficiently than untreated matrices (Brochure). GE Healthcare Life Sciences, UK limited

8. Whatman Inc. [2003-2010]; FTA- A highly flexible technology used widely in a range of technology (Brochure).GE Health Care Life Sciences, UK limited.

9. Lutz Roewer. Y chromosome STR typing in crime casework.Forensic Sci Med Pathol.2009;5:77-84

10. John M. Butler and Dennis J. Reeder (NIST Biochemical Science Division).Short Tandem Repeat DNA Internet Database, Forensic STR Information. Available from: http://www.cstl.nist.gov/strbase/

11. Beckett, S.M., S.J. Laughton, L.D. Pozza ,G. B. Mc Cowage, G. Marshall, R.J. Cohn, E. Milne, and L.J. Ashton. Buccal swabs and treated cards: methodological considerations for molecular epidemiologic. Am. J. Epidemiol.2008;167:1260-1267.

12. Zhou, H., J.G.H. Hickford, and Q. Fang. A two-step procedure for extracting genomic DNA from dried blood spots on filter paper for polymerase chain reaction amplification. Anal. Biochem. 2006; 354:159-161.

13. Hansen, T.V.O., M.K. Simonsen, F.C. Nielsen, and Y.A. Hundrup. Collection of blood, saliva, and buccal cell samples in a pilot study on the danish nurse cohort: comparison of the response rate and quality of genomic DNA. Cancer Epidemiol. Biomarkers Prev. 2007;16:2072- 2076
14. Passmore, L.A., B. Kaesmann-Kellner, and B.H.F. Weber. Novel and recurrent mutations in the tyrosinase gene and the $\mathrm{P}$ gene in the German albino population. Hum. Genet. 1999;105:200-210.

15. Walker AH, Najarian D, White DL, et al. Collection of genomic DNA by buccal swabs for polymerase chain reaction-based biomarker assays. Environ Health Perspect 1999;107:517 - 20.

16. Kozlowski LT, Vogler GR, Vandenbergh DJ, et al. Using a telephone survey to acquire genetic and behavioral data related to cigarette smoking in "madeanonymous" and "registry" samples. Am J Epidemiol 2002;156:68- 77.

17. King IB, Satia-Abouta J, Thornquist MD, et al. Buccal cell DNA yield, quality, and collection costs: comparison of methods for largescale studies. Cancer Epidemiol Biomarkers Prev 2002;11:1130 - 3.

18. Garcia-Closas M, Egan KM, Abruzzo J, et al. Collection of genomic DNA from adults in epidemiological studies by buccal cytobrush and mouthwash. Cancer Epidemiol Biomarkers Prev 2001;10:687 - 96.

19. Le Marchand L, Lum-Jones A, Saltzman B, et al. Feasibility of collecting buccal cell DNA by mail in a cohort study. Cancer Epidemiol Biomarkers Prev 2001;10:701 - 3.

20. Yang YG, Kim JY, Song YH, Kim DS. A novel buffer system, AnyDirect, can improve polymerase chain reaction from whole blood without DNA isolation. Clin Chim Acta 2007;380:112-7.

21. Yang YG, Kim JY, Soh MS, Kim DS. A simple and rapid gene amplification from Arabidopsis leaves using AnyDirect system. J Biochem Mol Biol 2007;40(3):444-7.

22. McCusker J, Dawson MT, Noone D, Gannon F, Smith T. Improved method for direct PCR amplification from whole blood. Nucleic Acids Res 1992; 20:6747.

23. Park SJ, Woo KM, Oh HH, Kim SH, Lee SH. Population data of the 25 STR loci in Koreans. J Forensic Sci 2005;50:710-2.

24. Yang YG, Kim JY, Kim SW, Lee SG, Inventors. Methods for performing direct enzymatic reactions involving nucleic acid molecules. Patent WO 090987 (Rep. of Korea PCT / KR 000457) 2006

\section{How to cite this article:}

Patel Jignal, M.G.Shaikh and Marjadi Darshan., Forensic Conception: Dna Typing of Fta Spotted Samples. J App Biol Biotech, 2014; 2 (04): 021-029. 